\title{
Cyclin D associated events in G1
}

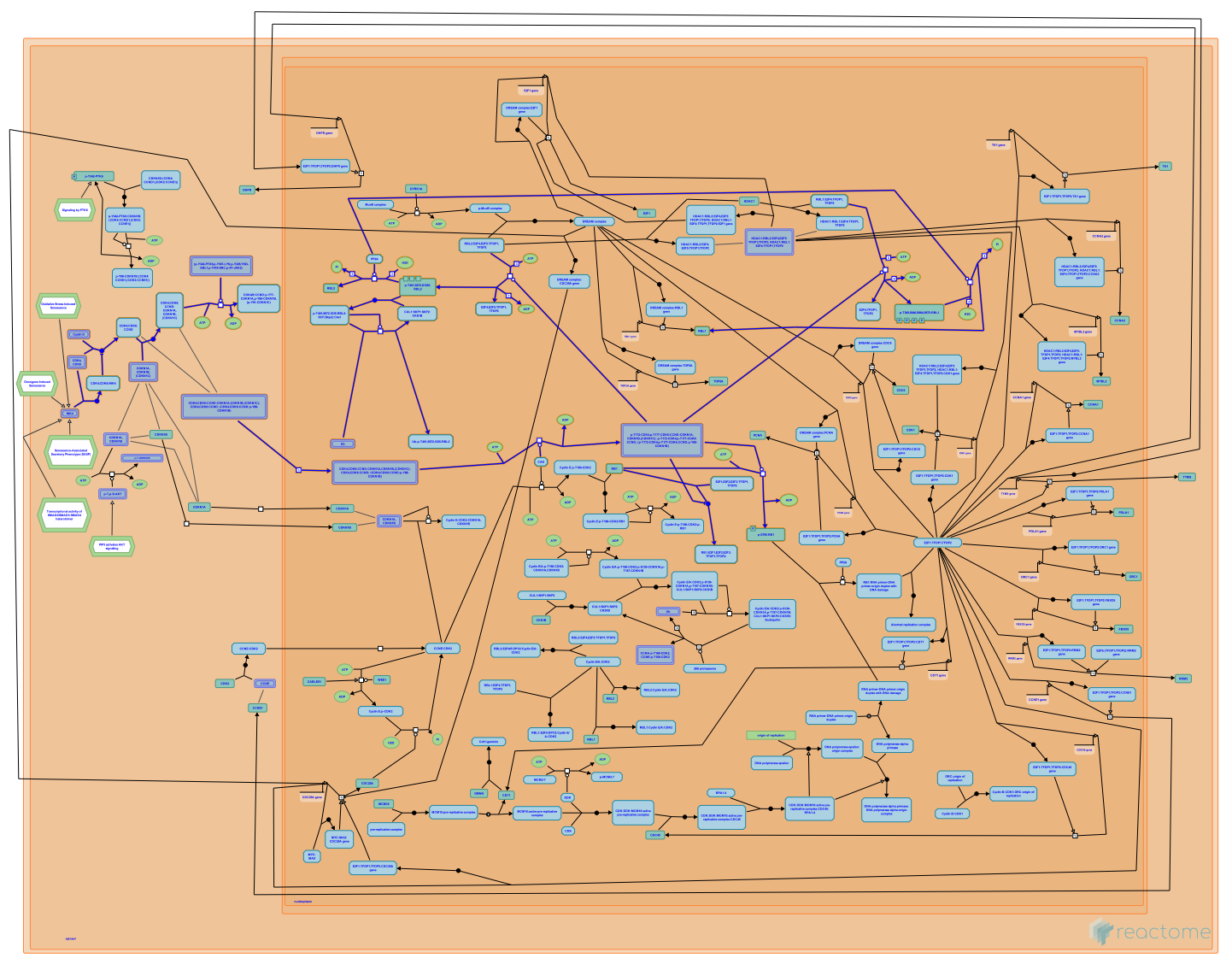

D'Eustachio, P., Grana, X., MacPherson, D., Manfredi, JJ., Matthews, L., O'Donnell, M., Orlic-Milacic, M., Roger, PP., Samarajiwa, S., Walworth, N.

European Bioinformatics Institute, New York University Langone Medical Center, Ontario Institute for Cancer Research, Oregon Health and Science University.

The contents of this document may be freely copied and distributed in any media, provided the authors, plus the institutions, are credited, as stated under the terms of Creative Commons Attribution 4.0 International (CC BY 4.0) License. For more information see our license. 


\section{Introduction}

Reactome is open-source, open access, manually curated and peer-reviewed pathway database. Pathway annotations are authored by expert biologists, in collaboration with Reactome editorial staff and crossreferenced to many bioinformatics databases. A system of evidence tracking ensures that all assertions are backed up by the primary literature. Reactome is used by clinicians, geneticists, genomics researchers, and molecular biologists to interpret the results of high-throughput experimental studies, by bioinformaticians seeking to develop novel algorithms for mining knowledge from genomic studies, and by systems biologists building predictive models of normal and disease variant pathways.

The development of Reactome is supported by grants from the US National Institutes of Health (P41 HG003751), University of Toronto (CFREF Medicine by Design), European Union (EU STRP, EMI-CD), and the European Molecular Biology Laboratory (EBI Industry program).

\section{Literature references}

Fabregat, A., Sidiropoulos, K., Viteri, G., Forner, O., Marin-Garcia, P., Arnau, V. et al. (2017). Reactome pathway analysis: a high-performance in-memory approach. BMC bioinformatics, 18, 142. $\lambda$

Sidiropoulos, K., Viteri, G., Sevilla, C., Jupe, S., Webber, M., Orlic-Milacic, M. et al. (2017). Reactome enhanced pathway visualization. Bioinformatics, 33, 3461-3467.

Fabregat, A., Jupe, S., Matthews, L., Sidiropoulos, K., Gillespie, M., Garapati, P. et al. (2018). The Reactome Pathway Knowledgebase. Nucleic Acids Res, 46, D649-D655.

Fabregat, A., Korninger, F., Viteri, G., Sidiropoulos, K., Marin-Garcia, P., Ping, P. et al. (2018). Reactome graph database: Efficient access to complex pathway data. PLoS computational biology, 14, e1005968. $\lambda$

Reactome database release: 68

This document contains 1 pathway and 14 reactions (see Table of Contents) 


\section{Cyclin D associated events in G1 $\nearrow$}

Stable identifier: R-HSA-69231

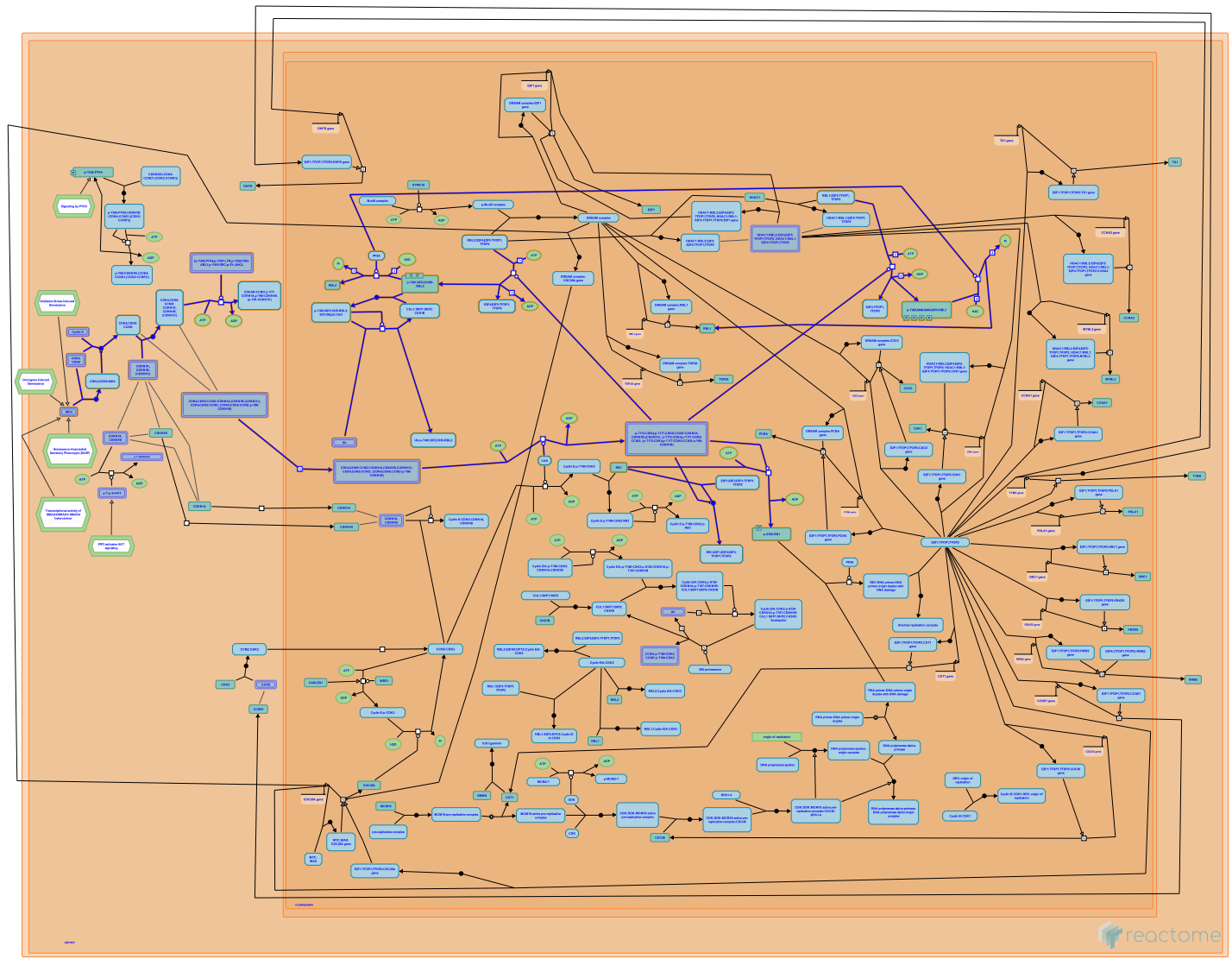

Three D-type cyclins are essential for progression from G1 to S-phase. These D cyclins bind to and activate both CDK4 and CDK6. The formation of all possible complexes between the D-type cyclins and CDK4/6 is promoted by the proteins, p21(CIP1/WAF1) and p27(KIP1). The cyclin-dependent kinases are then activated due to phosphorylation by CAK. The cyclin dependent kinases phosphorylate the RB1 protein and RB1-related proteins p107 (RBL1) and p130 (RBL2). Phosphorylation of RB1 leads to release of activating E2F transcription factors (E2F1, E2F2 and E2F3). After repressor E2Fs (E2F4 and E2F5) dissociate from phosphorylated RBL1 and RBL2, activating E2Fs bind to E2F promoter sites, stimulating transcription of cell cycle genes, which then results in proper G1/S transition. The binding and sequestration of p27Kip may also contribute to the activation of CDK2 cyclin E/CDK2 cyclin A complexes at the G1/S transition (Yew et al., 2001).

\section{Editions}

2016-11-04

2016-12-01
Revised

Edited
Roger, PP. Orlic-Milacic, M. 


\section{Association of INK4 with CDK4/6 7}

Location: Cyclin D associated events in G1

Stable identifier: R-HSA-182594

Type: binding

Compartments: cytosol

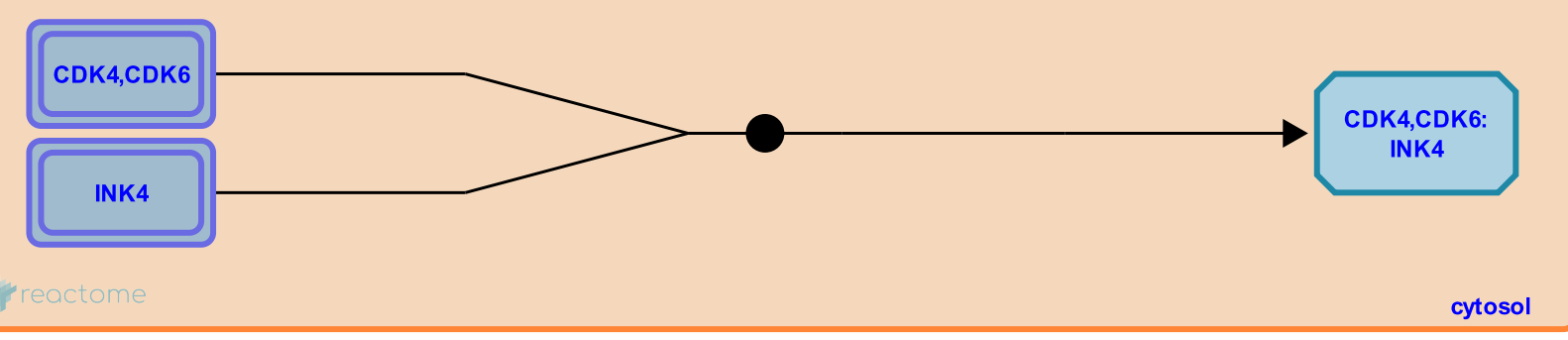

Prior to mitogen activation, the inhibitory proteins of the INK4 family (p15, p16, p18, and p19) associate with the catalytic domains of free CDK4 and CDK6, preventing their association with D type cyclins (CCND1, CCND2 and CCND3), and thus their activation (Serrano et al. 1993, Hannon and Beach 1994, Guan et al. 1994, Guan et al. 1996, Parry et al. 1995). Inactivation and defects of RB1 strongly upregulate p16-INK4A (Parry et al. 1995).

\section{Literature references}

Serrano, M., Hannon, GJ., Beach, D. (1993). A new regulatory motif in cell-cycle control causing specific inhibition of cyclin D/CDK4. Nature, 366, 704-7. 7

Hannon, GJ., Beach, D. (1994). p15INK4B is a potential effector of TGF-beta-induced cell cycle arrest. Nature, 371, 257-61. $>$

Guan, KL., Jenkins, CW., Li, Y., Nichols, MA., Wu, X., O'Keefe, CL. et al. (1994). Growth suppression by p18, a p16INK4/MTS1- and p14INK4B/MTS2-related CDK6 inhibitor, correlates with wild-type pRb function. Genes Dev, 8 , 2939-52. ᄀ

Guan, KL., Jenkins, CW., Li, Y., O'Keefe, CL., Noh, S., Wu, X. et al. (1996). Isolation and characterization of p19INK4d, a p16-related inhibitor specific to CDK6 and CDK4. Mol Biol Cell, 7, 57-70. 7

Parry, D., Bates, S., Mann, DJ., Peters, G. (1995). Lack of cyclin D-Cdk complexes in Rb-negative cells correlates with high levels of p16INK4/MTS1 tumour suppressor gene product. EMBO J., 14, 503-11. \

\section{Editions}

\begin{tabular}{|c|c|c|}
\hline 2005-10-07 & Edited & Matthews, L. \\
\hline 2006-07-11 & Authored & Matthews, L. \\
\hline 2013-09-03 & Reviewed & Samarajiwa, S. \\
\hline $2016-10-07$ & Edited & Orlic-Milacic, M. \\
\hline 2016-11-04 & Reviewed & Roger, PP. \\
\hline
\end{tabular}




\section{Formation of CDK4/6:CCND complexes $\nearrow$}

Location: Cyclin D associated events in G1

Stable identifier: R-HSA-8941895

Type: binding

Compartments: cytosol

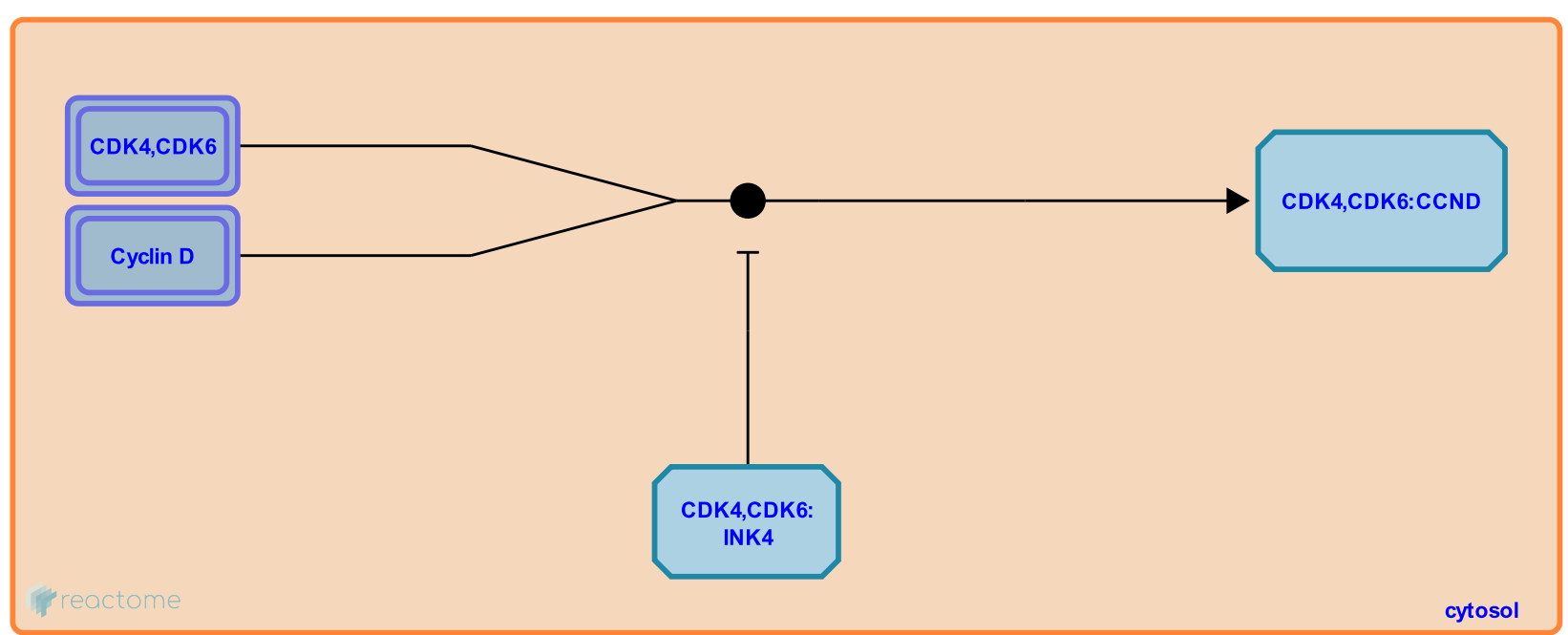

The cyclin dependent kinase CDK4 or CDK6 forms a complex with one of the cyclin D family (CCND) members: cyclin D1 (CCND1), cyclin D2 (CCND2) or cyclin D3 (CCND3) (Matsushime et al. 1992, Meyerson and Harlow 1994, La Baer et al. 1997, Bagui et al. 2003, Cerqueira et al. 2014). This association is regulated by mitogenic pathways (Cheng et al. 1998, Depoortere et al. 1998). While the binding of Cip/Kip CDK-inhibitors (CDKIs) (CDKNA1 - p21Cip, CDKN1B - p27Kip or CDKN1C - p57Kip2) stabilizes CDK4/6:CCND complexes by decreasing their dissociation rate (La Baer et al. 1997; reviewed by Sherr and Roberts 1999), CIP/KIP CDKIs are not needed for binding of CDK4 or CDK6 to CCNDs and activity of CDK4/6:CCND complexes (Bagui et al. 2000, Sugimoto et al. 2002, Bagui et al. 2003, Cerqueira et al. 2014; reviewed by Bockstaele et al 2006).

Followed by: Cip/Kip CDK inhibitors bind CDK4/6:CCND complexes, Translocation of CDK4/6:CCND complexes from the cytoplasm to the nucleus

\section{Literature references}

LaBaer, J., Garrett, MD., Stevenson, LF., Slingerland, JM., Sandhu, C., Chou, HS. et al. (1997). New functional activities for the p21 family of CDK inhibitors. Genes Dev, 11, 847-62. 7

Bagui, TK., Mohapatra, S., Haura, E., Pledger, WJ. (2003). P27Kip1 and p21Cip1 are not required for the formation of active D cyclin-cdk4 complexes. Mol. Cell. Biol., 23, 7285-90. $\lambda$

Cerqueira, A., Martín, A., Symonds, CE., Odajima, J., Dubus, P., Barbacid, M. et al. (2014). Genetic characterization of the role of the Cip/Kip family of proteins as cyclin-dependent kinase inhibitors and assembly factors. Mol. Cell. Biol., 34, 1452-9. त

Meyerson, M., Harlow, E. (1994). Identification of G1 kinase activity for cdk6, a novel cyclin D partner. Mol. Cell. Biol. , 14, 2077-86. त

Matsushime, H., Ewen, ME., Strom, DK., Kato, JY., Hanks, SK., Roussel, MF. et al. (1992). Identification and properties of an atypical catalytic subunit (p34PSK-J3/cdk4) for mammalian D type G1 cyclins. Cell, 71, 323-34. ㅈ 


\section{Editions}

2006-07-03

2016-10-07

2016-10-19

2016-11-04
Authored, Edited

$$
\text { Edited }
$$

Reviewed

Reviewed
Matthews, L.

Orlic-Milacic, M.

D'Eustachio, P.

Roger, PP. 


\section{Cip/Kip CDK inhibitors bind CDK4/6:CCND complexes $\nearrow$}

Location: Cyclin D associated events in G1

Stable identifier: R-HSA-8941915

Type: binding

Compartments: cytosol

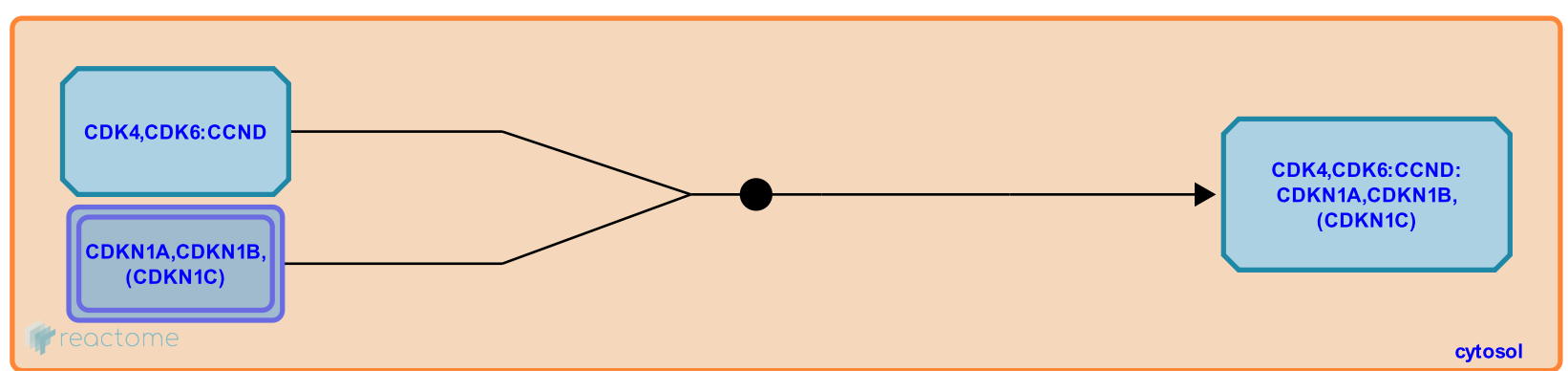

Binding of CDK inhibitors of the Cip/Kip family, CDKNA1 (p21Cip), CDKN1B (p27Kip) or CDKN1C (p57Kip2) to the complex of CDK4 or CDK6 and cyclin D family members (CCND1, CCND2 or CCND3), inhibits kinase activity of the CDK4/6:CCND complexes but at the same time increases their stability and, hence, their abundance (La Baer et al. 1997, Bagui et al. 2003, Cerqueira et al. 2014; reviewed by Bockstaele et al. 2006). Based on structural studies of CDKN1B, Cip/Kip inhibitors simultaneously interact with CDK4/6 and CCNDs (Liu et al. 2010). Phosphorylation of CDKN1B on threonine residues T157 and T198 by activated AKT in early G1 may precede binding of CDKN1B to CDK4/6:CCND complexes (Larrea et al. 2008).

\section{Preceded by: Formation of CDK4/6:CCND complexes}

Followed by: Translocation of CDK4/6:CCND complexes from the cytoplasm to the nucleus, Tyrosine kinases phosphorylate Cip/Kip inhibitors bound to CDK4/6:CCND complexes

\section{Literature references}

LaBaer, J., Garrett, MD., Stevenson, LF., Slingerland, JM., Sandhu, C., Chou, HS. et al. (1997). New functional activities for the p21 family of CDK inhibitors. Genes Dev, 11, 847-62. ᄀ

Bagui, TK., Mohapatra, S., Haura, E., Pledger, WJ. (2003). P27Kip1 and p21Cip1 are not required for the formation of active D cyclin-cdk4 complexes. Mol. Cell. Biol., 23, 7285-90. \

Cerqueira, A., Martín, A., Symonds, CE., Odajima, J., Dubus, P., Barbacid, M. et al. (2014). Genetic characterization of the role of the Cip/Kip family of proteins as cyclin-dependent kinase inhibitors and assembly factors. Mol. Cell. Biol., 34, 1452-9. ᄀ

Liu, S., Bolger, JK., Kirkland, LO., Premnath, PN., McInnes, C. (2010). Structural and functional analysis of cyclin D1 reveals p27 and substrate inhibitor binding requirements. ACS Chem. Biol., 5, 1169-82. 7

Bockstaele, L., Coulonval, K., Kooken, H., Paternot, S., Roger, PP. (2006). Regulation of CDK4. Cell Div, 1, 25. ^

\section{Editions}

\begin{tabular}{|ccc}
\hline $2006-07-03$ & Authored & Matthews, L. \\
\hline $2016-10-07$ & Edited & Orlic-Milacic, M. \\
\hline $2016-10-19$ & Reviewed & D'Eustachio, P. \\
\hline $2016-11-04$ & Reviewed & Roger, PP. \\
\hline
\end{tabular}




\section{Tyrosine kinases phosphorylate Cip/Kip inhibitors bound to CDK4/6:CCND com- plexes $\lambda$}

Location: Cyclin D associated events in G1

Stable identifier: R-HSA-8942607

Type: transition

Compartments: cytosol

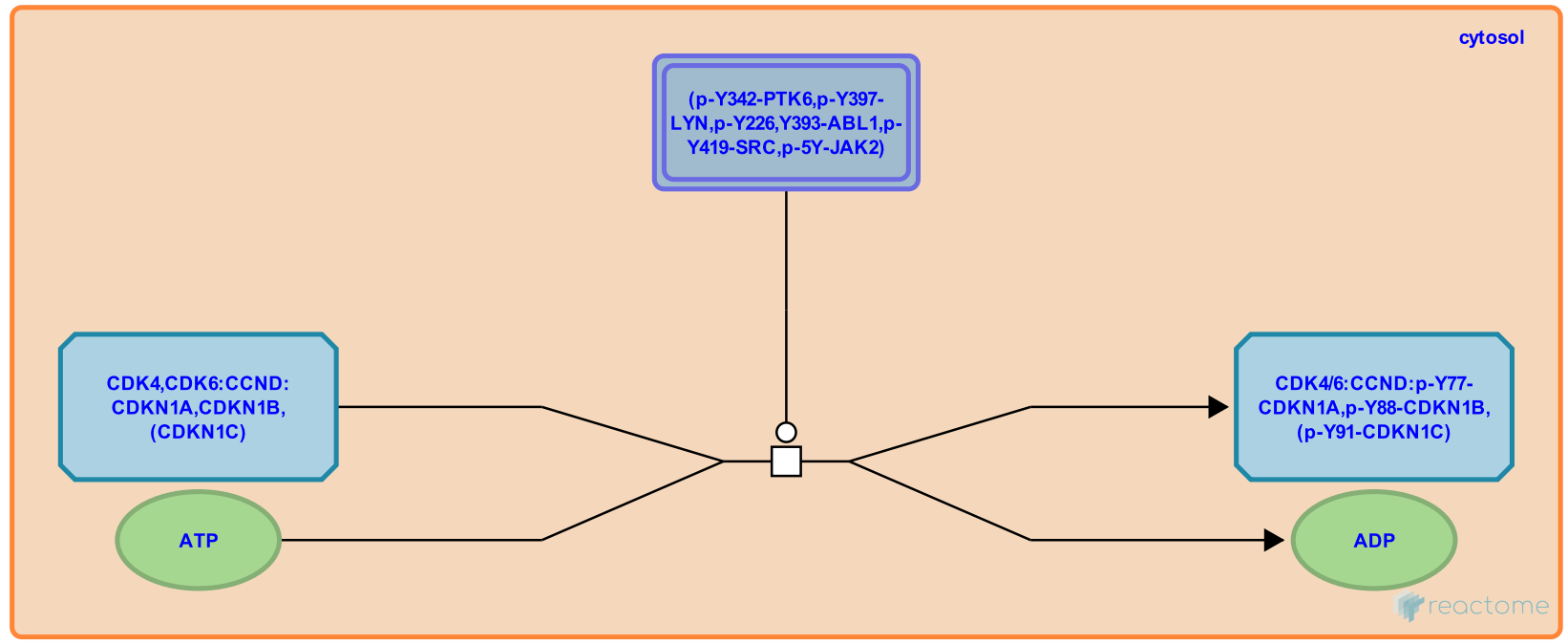

Phosphorylation of Cip/Kip cyclin-dependent kinase (CDK) inhibitors CDKN1A (p21Cip), CDKN1B (p27Kip1) and CDKN1C (p57Kip2) on conserved tyrosine residues Y77, Y88 and Y91, respectively, can convert them from bound inhbitors to bound non-inhibitors of CDK4 or CDK6 complexes with D cyclins by dislodging them from the active site of CDK4 or CDK6. This mechanism was studied in most detail on the example of CDKN1B associated with the CDK2:CCNA complex (Grimmler et al. 2007) and the CDK4:CCND1 complex (James et al. 2008, Patel et al. 2015). For a review of this topic, please refer to Blain 2008.

CDKN1A can be phosphorylated at tyrosine residue Y77 by protein tyrosine kinase ABL1 (Hukkelhoven et al. 2012). CDKN1B can be phosphorylated at tyrosine residue Y88, and probably also at the adjacent Y89, by protein tyrosine kinases ABL1 (Grimmler et al. 2007, James et al. 2008, Ray et al. 2009, Ou et al. 2011), LYN (Grimmler et al. 2007), SRC (Larrea et al. 2008), JAK2 (Jakel et al. 2011) and PTK6 (Patel et al. 2015). CDKN1C can be phosphorylated at tyrosine residue Y91 by protein tyrosine kinase ABL1 (Borriello et al. 2011).

Dislodgment of the tyrosine phosphorylated 3-10 helix of Cip/Kip CDK inhibitors from the active site of cyclin D-bound CDK4 or CDK6 results in increased catalytic activity of CDK4 or CDK6 by allowing ATP binding to the active site, but also by enabling activating phosphorylation of the T-loop of CDK4 or CDK6 phosphorylation by CDK7 in complex with cyclin H (Ray et al. 2009).

SRC-mediated phosphorylation of CDKN1B on tyrosine residue Y88 was shown to reduce protein stability of CDKN1B (Chu et al. 2007).

Without overexpression of BCR-ABL or SRC-family tyrosine kinases in several cell systems, tyrosine phosphorylated p27 is either undetectable or a very low abundance species (Ishida et al. 2000, Jaimes et al. 2008, Grimmler et al. 2007) that does not bind preferentially to CDK4 (Jaimes et al. 2008). Therefore, tyrosine phosphorylation of p27 is unlikely to be the sole explanation of the full activity of p27-bound CDK4:CCND complexes reported in previous studies (Blain et al. 1997, Coulonval et al. 2003, Bockstaele et 
al. 2006). It has been proposed that stoichiometry of the Cip/Kip complex with CDK4 or CDK6 and cyclin $\mathrm{D}$, in addition to or alternative to tyrosine phosphorylation of Cip/Kip CDK inhibitors, determines their inhibitory role where binding of more than one molecule of CDKN1A, CDKN1B or CDKN1C would be needed to achieve inhibition of the CDK4/6:CCND complex (reviewed by Paternot et al. 2010).

Preceded by: Cip/Kip CDK inhibitors bind CDK4/6:CCND complexes

Followed by: Translocation of CDK4/6:CCND complexes from the cytoplasm to the nucleus

\section{Literature references}

Grimmler, M., Wang, Y., Mund, T., Cilensek, Z., Keidel, EM., Waddell, MB. et al. (2007). Cdk-inhibitory activity and stability of p27Kip1 are directly regulated by oncogenic tyrosine kinases. Cell, 128, 269-80.

Patel, P., Asbach, B., Shteyn, E., Gomez, C., Coltoff, A., Bhuyan, S. et al. (2015). Brk/Protein tyrosine kinase 6 phosphorylates p27KIP1, regulating the activity of cyclin D-cyclin-dependent kinase 4. Mol. Cell. Biol., 35, 1506-22.

Borriello, A., Caldarelli, I., Bencivenga, D., Cucciolla, V., Oliva, A., Usala, E. et al. (2011). p57Kip2 is a downstream effector of BCR-ABL kinase inhibitors in chronic myelogenous leukemia cells. Carcinogenesis, 32, 10-8. 7

Hukkelhoven, E., Liu, Y., Yeh, N., Ciznadija, D., Blain, SW., Koff, A. (2012). Tyrosine phosphorylation of the p21 cyclin-dependent kinase inhibitor facilitates the development of proneural glioma. J. Biol. Chem., 287, 38523-30. ㄱ

Ou, L., Ferreira, AM., Otieno, S., Xiao, L., Bashford, D., Kriwacki, RW. (2011). Incomplete folding upon binding mediates Cdk4/cyclin D complex activation by tyrosine phosphorylation of inhibitor p27 protein. J. Biol. Chem., 286, 30142-51.

\section{Editions}

$\begin{array}{ccc}\text { 2016-10-19 } & \text { Authored } & \text { Orlic-Milacic, M. } \\ 2016-11-04 & \text { Reviewed } & \text { Roger, PP. } \\ 2016-12-01 & \text { Edited } & \text { Orlic-Milacic, M. }\end{array}$




\section{Translocation of CDK4/6:CCND complexes from the cytoplasm to the nucleus $\lambda$}

Location: Cyclin D associated events in G1

Stable identifier: R-HSA-8942803

Type: omitted

Compartments: nuclear envelope

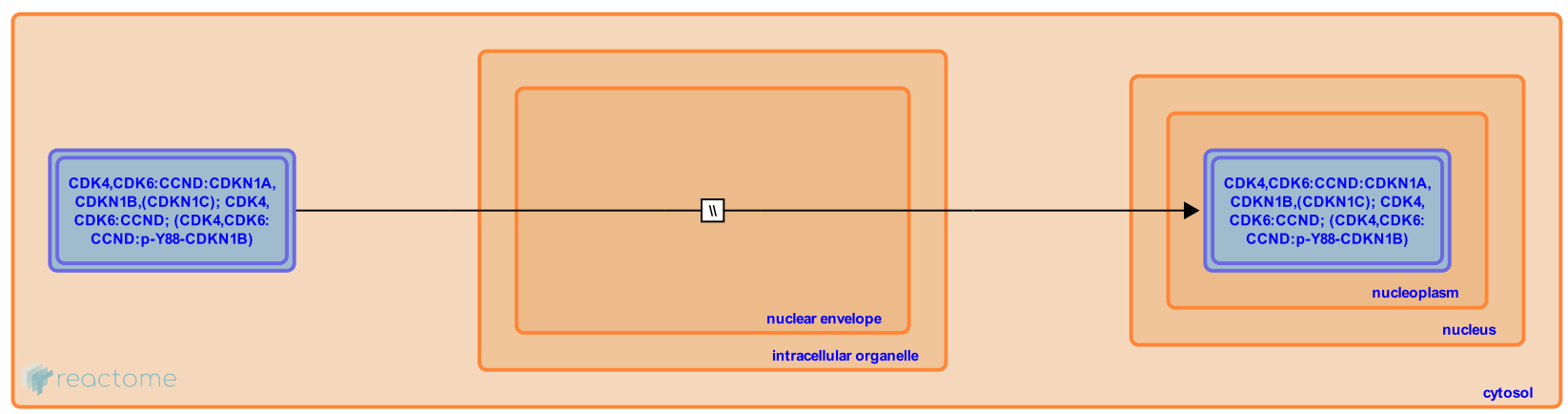

Cyclin D:CDK4/6 complexes translocate to the nucleus from the cytoplasm at G1/S transition (Wang et al. 2008). This nuclear accumulation requires the binding to the Cip/Kip cyclin-dependent kinase (CDK) inhibitors CDKN1A (p21Cip), CDKN1B (p27Kip1) and probably also CDKN1C (p57Kip2), and the C-terminal NLS sequence of Cip/Kip proteins (LaBaer et al. 1997, Reynisdottir and Massagué 1997). Phosphorylations close to the NLS (at T145 in CDKN1A and T157 in CDKN1B) impede the nuclear localization of Cip/Kip proteins (Zhou et al. 2001, Shin et al. 2005) and potentially of CDK4/6:CCND complexes. One study suggested that tyrosine phosphorylation of p27 (CDKN1B) could facilitate the nuclear import of p27-bound CDK4 (Kardinal et al. 2006). However, others observed that endogenous Y88-phosphorylated p27Kip1, as well as overexpressed p27Kip1 phosphorylated by JAK2 was predominantly cytoplasmic (Jäkel et al. 2011). Effects of tyrosine phosphorylation of CDKN1A and CDKN1C on their localization have not been investigated.

In the absence of Cip/Kip proteins, a small number of CDK4/6:CCND complexes enter the nucleus through an unknown mechanism and phosphorylate target proteins (Bagui et al. 2003).

Preceded by: Cip/Kip CDK inhibitors bind CDK4/6:CCND complexes, Formation of CDK4/6:CCND complexes, Tyrosine kinases phosphorylate Cip/Kip inhibitors bound to CDK4/6:CCND complexes

Followed by: CDK4/6:CCND complexes are activated by T-loop phosphorylation of CDK4/6

\section{Literature references}

LaBaer, J., Garrett, MD., Stevenson, LF., Slingerland, JM., Sandhu, C., Chou, HS. et al. (1997). New functional activities for the p21 family of CDK inhibitors. Genes Dev, 11, 847-62. ᄀ

Kardinal, C., Dangers, M., Kardinal, A., Koch, A., Brandt, DT., Tamura, T. et al. (2006). Tyrosine phosphorylation modulates binding preference to cyclin-dependent kinases and subcellular localization of p27Kip1 in the acute promyelocytic leukemia cell line NB4. Blood, 107, 1133-40. $\lambda$

Wang, Z., Xie, Y., Zhang, L., Zhang, H., An, X., Wang, T. et al. (2008). Migratory localization of cyclin D2-Cdk4 complex suggests a spatial regulation of the G1-S transition. Cell Struct. Funct., 33, 171-83.

Jäkel, H., Weinl, C., Hengst, L. (2011). Phosphorylation of p27Kip1 by JAK2 directly links cytokine receptor signaling to cell cycle control. Oncogene, 30, 3502-12.

Reynisdóttir, I., Massagué, J. (1997). The subcellular locations of p15(Ink4b) and p27(Kip1) coordinate their inhibitory interactions with cdk4 and cdk2. Genes Dev., 11, 492-503. 
Editions

2006-07-11

Edited

Matthews, L.

2016-10-20

Authored

Orlic-Milacic, M.

2016-11-04

Reviewed

Roger, PP.

2016-12-01

Edited

Orlic-Milacic, M. 


\section{CDK4/6:CCND complexes are activated by T-loop phosphorylation of CDK4/6 $\lambda$}

Location: Cyclin D associated events in G1

Stable identifier: R-HSA-8942836

Type: transition

Compartments: nucleoplasm

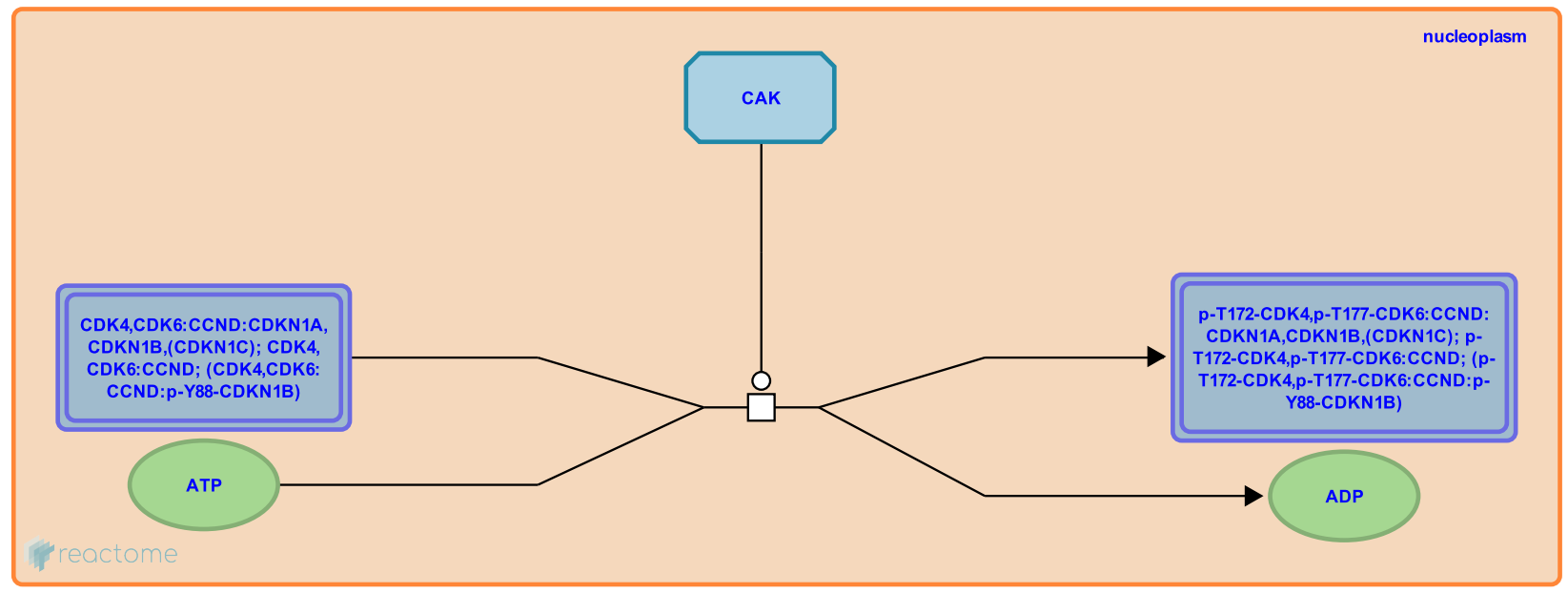

T-loop phosphorylation of CDK4 and CDK6 on threonine residues T172 and T177, respectively, is necessary for catalytic activity of complexes of CDK4 and CDK6 with D-type cyclins (CCND1, CCND2 and CCND3) (Kato, Matsuoka, Strom and Sherr 1994, Merzel-Schachter et al. 2013, Bisteau et al. 2013). These phosphorylations depend on prior D type cyclin binding (Kato, Matsuoka, Polyak et al. 1994, Bockstaele et al. 2006). The T-loop phosphorylation is not precluded by the association of CDK4/6:CCND complexes to Cip/Kip cyclin-dependent kinase (CDK) inhibitors CDKN1A (p21Cip) and CDKN1B (p27Kip1), however high expression levels of CDKN1B reduce the T172 phosphorylation of CDK4 (Kato, Matsuoka, Polyak et al. 1994, Bockstaele et al. 2006, Ray et al. 2009). Phosphorylation at tyrosine residue Y89 of CDKN1B (p27Kip1) bound to CDK4:CCND complexes was found to be necessary for phosphorylation of CDK4 by the CAK complex (composed of CDK7, CCNH and MAT1) in vitro, but not for the phosphorylation by CSK1 of S. pombe (Ray et al. 2009). T-loop phosphorylations of CDK4 and CDK6 are differentially regulated (Bockstaele et al. 2009). Especially, the T172 phosphorylation of CDK4 is strictly controlled by mitogenic and antimitogenic pathways (Paternot and Roger 2009), and it can be differentially regulated in cyclin D1:CDK4 and cyclin D3:CDK4 complexes (reviewed by Paternot et al. 2010). The T-loop T172 phosphorylation motif of CDK4 differs from the other cell cycle CDKs, including CDK6, by the presence of an adjacent proline residue (P173) that is evolutionarily conserved. This proline residue is required for T172 phosphorylation of CDK4 in vivo, but not for its in vitro phosphorylation by CAK. This indicates that CDK4 might be activated by other proline-directed kinases in vivo (Bockstaele et al. 2009). Nevertheless, in HCT116 colon carcinoma cell line, the activity of CDK7 is required for the T172 phosphorylation of CDK4 and the activity of CDK4/6:CCND complexes (Merzel Schachter et al. 2013, Bisteau et al. 2013). T170 phosphorylation of CDK7 facilitates the activity of CAK on CDK4 (Merzel Schachter et al. 2013). However, CDK7 inhibition in HCT116 cells does not preclude the T172 phosphorylation of CDK4:CCND complexes that are not associated with CDKN1A (Bisteau et al. 2013).

Phosphorylation of CDKN1A at serine residue S130 by CDK4/6 and CDK2 has been implicated as a pre-requisite for CAK-mediated phosphorylation of CDKN1A-bound CDK4 (Bisteau et al. 2013). Other kinases involved in phosphorylation of CDK4 at T172 remain to be defined (Bockstaele et al. 2009, Bisteau et al. 2013, reviewed by Paternot et al. 2010).

Preceded by: Translocation of CDK4/6:CCND complexes from the cytoplasm to the nucleus 
Followed by: Cyclin D:CDK4/6 mediated phosphorylation of p107 (RBL1) and dissociation of phosphorylated p107 (p-RBL1) from DP1:E2F4 complex, Cyclin D:Cdk4/6 mediated phosphorylation of p130 (RBL2) and dissociation of phosphorylated p130 (RBL2) from DP1:E2F4/5 complex, Cyclin D:CDK4/6 phosphorylates RB1 and prevents RB1 binding to E2F1/2/3:DP1/2 complexes

\section{Literature references}

Bockstaele, L., Kooken, H., Libert, F., Paternot, S., Dumont, JE., de Launoit, Y. et al. (2006). Regulated activating Thr172 phosphorylation of cyclin-dependent kinase 4(CDK4): its relationship with cyclins and CDK \&quot;inhibitors\&quot;. Mol Cell Biol, 26, 5070-85. 入

Merzel Schachter, MM., Merrick, KA., Larochelle, S., Hirschi, A., Zhang, C., Shokat, KM. et al. (2013). A Cdk7-Cdk4 Tloop phosphorylation cascade promotes G1 progression. Mol. Cell, 50, 250-60.

Bockstaele, L., Bisteau, X., Paternot, S., Roger, PP. (2009). Differential regulation of cyclin-dependent kinase 4 (CDK4) and CDK6, evidence that CDK4 might not be activated by CDK7, and design of a CDK6 activating mutation . Mol. Cell. Biol., 29, 4188-200. T

Ray, A., James, MK., Larochelle, S., Fisher, RP., Blain, SW. (2009). p27Kip1 inhibits cyclin D-cyclin-dependent kinase 4 by two independent modes. Mol. Cell. Biol., 29, 986-99. $\nearrow$

Bisteau, X., Paternot, S., Colleoni, B., Ecker, K., Coulonval, K., De Groote, P. et al. (2013). CDK4 T172 phosphorylation is central in a CDK7-dependent bidirectional CDK4/CDK2 interplay mediated by 21 phosphorylation at the restriction point. PLoS Genet., 9, e1003546. \

\section{Editions}

\begin{tabular}{|ccc}
\hline $2003-06-05$ & Authored & O'Donnell, M., Walworth, N. \\
\hline $2005-10-07$ & Edited & Matthews, L. \\
\hline $2016-10-20$ & Authored & Orlic-Milacic, M. \\
\hline $2016-11-04$ & Reviewed & Roger, PP. \\
\hline $2016-12-01$ & Edited & Orlic-Milacic, M. \\
\hline $2018-07-10$ & Reviewed & Manfredi, JJ. \\
\hline
\end{tabular}




\section{RB1 binds and inhibits E2F1/2/3:DP1/2 complexes $\neg$}

Location: Cyclin D associated events in G1

Stable identifier: R-HSA-9018017

Type: binding

Compartments: nucleoplasm

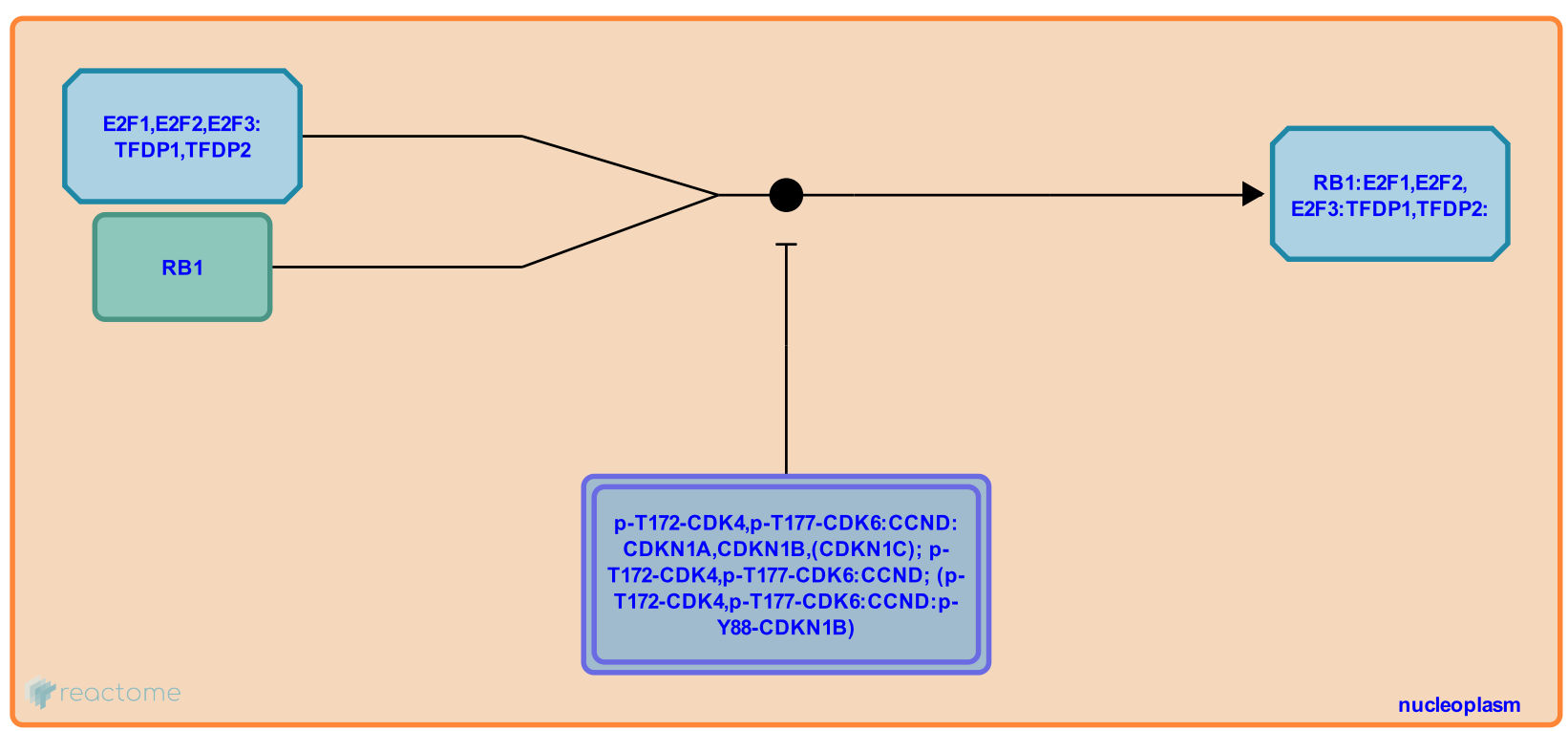

RB1 tumor suppressor, the product of the retinoblastoma susceptibility gene, binds to E2F transcription factors E2F1, E2F2 and E2F3, presumably heterodimerized with TFDP1 or TFDP2. The interaction involves the pocket domain of RB1. RB1 binding inhibits transcriptional activity of E2F1/2/3:TFDP1/2 complexes, resulting in prevention of G1/S transition (Chellappan et al. 1991, Bagchi et al. 1991, Chittenden et al. 1991, Lees et al. 1993, Hiebert 1993, Wu et al. 2001). Once RB1 is phosphorylated on serine residue S795 by Cyclin D:CDK4/6 complexes, it can no longer associate with and inhibit E2F1/2/3:TFDP1/2 complexes. Thus, CDK4/6-mediated phosphorylation of RB1 leads to transcriptional activation of E2F1/2/3 target genes needed for the $S$ phase of the cell cycle (Connell-Crowley et al. 1997).

\section{Literature references}

Connell-Crowley, L., Harper, JW., Goodrich, DW. (1997). Cyclin D1/Cdk4 regulates retinoblastoma protein-mediated cell cycle arrest by site-specific phosphorylation. Mol Biol Cell, 8, 287-301. ^

Chellappan, SP., Hiebert, S., Mudryj, M., Horowitz, JM., Nevins, JR. (1991). The E2F transcription factor is a cellular target for the RB protein. Cell, 65, 1053-61. $\lambda$

Bagchi, S., Weinmann, R., Raychaudhuri, P. (1991). The retinoblastoma protein copurifies with E2F-I, an E1A-regulated inhibitor of the transcription factor E2F. Cell, 65, 1063-72. ᄀ

Chittenden, T., Livingston, DM., Kaelin, WG. (1991). The T/E1A-binding domain of the retinoblastoma product can interact selectively with a sequence-specific DNA-binding protein. Cell, 65, 1073-82. $\nearrow$

Lees, JA., Saito, M., Vidal, M., Valentine, M., Look, T., Harlow, E. et al. (1993). The retinoblastoma protein binds to a family of E2F transcription factors. Mol. Cell. Biol., 13, 7813-25. ㅈ

\section{Editions}


Cyclin D:CDK4/6 phosphorylates RB1 and prevents RB1 binding to E2F1/2/3:DP1/2 complexes $\lambda$

Location: Cyclin D associated events in G1

Stable identifier: R-HSA-69227

Type: transition

Compartments: nucleoplasm

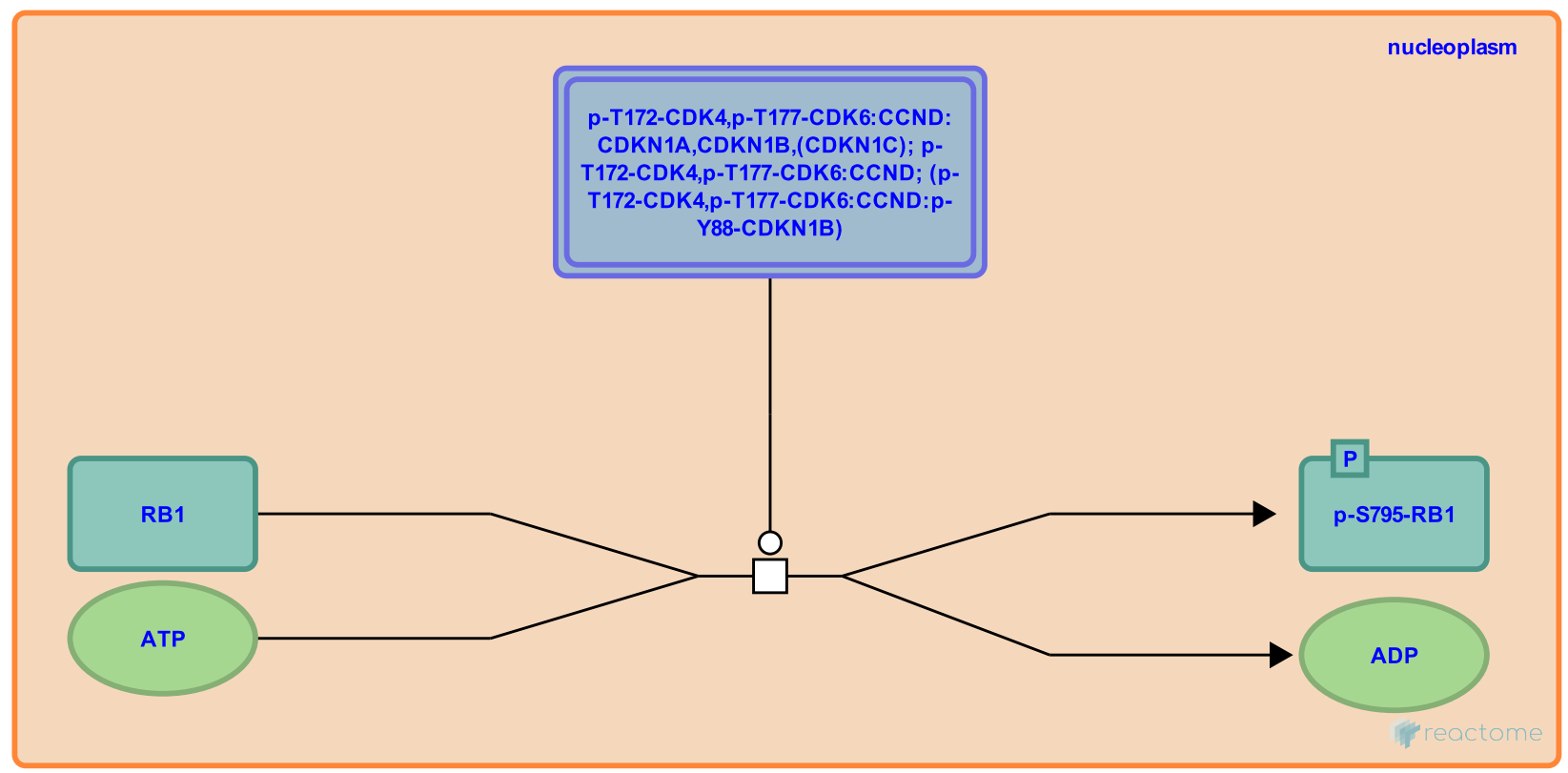

Cyclin D:Cdk4 mediated phosphorylation of RB1 releases RB1 from the transcriptional regulator E2F and activates E2F function.

Preceded by: CDK4/6:CCND complexes are activated by T-loop phosphorylation of CDK4/6

\section{Literature references}

Connell-Crowley, L., Harper, JW., Goodrich, DW. (1997). Cyclin D1/Cdk4 regulates retinoblastoma protein-mediated cell cycle arrest by site-specific phosphorylation. Mol Biol Cell, 8, 287-301. 7 


\section{Cyclin D:CDK4/6 mediated phosphorylation of p107 (RBL1) and dissociation of phos- phorylated p107 (p-RBL1) from DP1:E2F4 complex $\nearrow$}

Location: Cyclin D associated events in G1

Stable identifier: R-HSA-1226095

Type: transition

Compartments: nucleoplasm

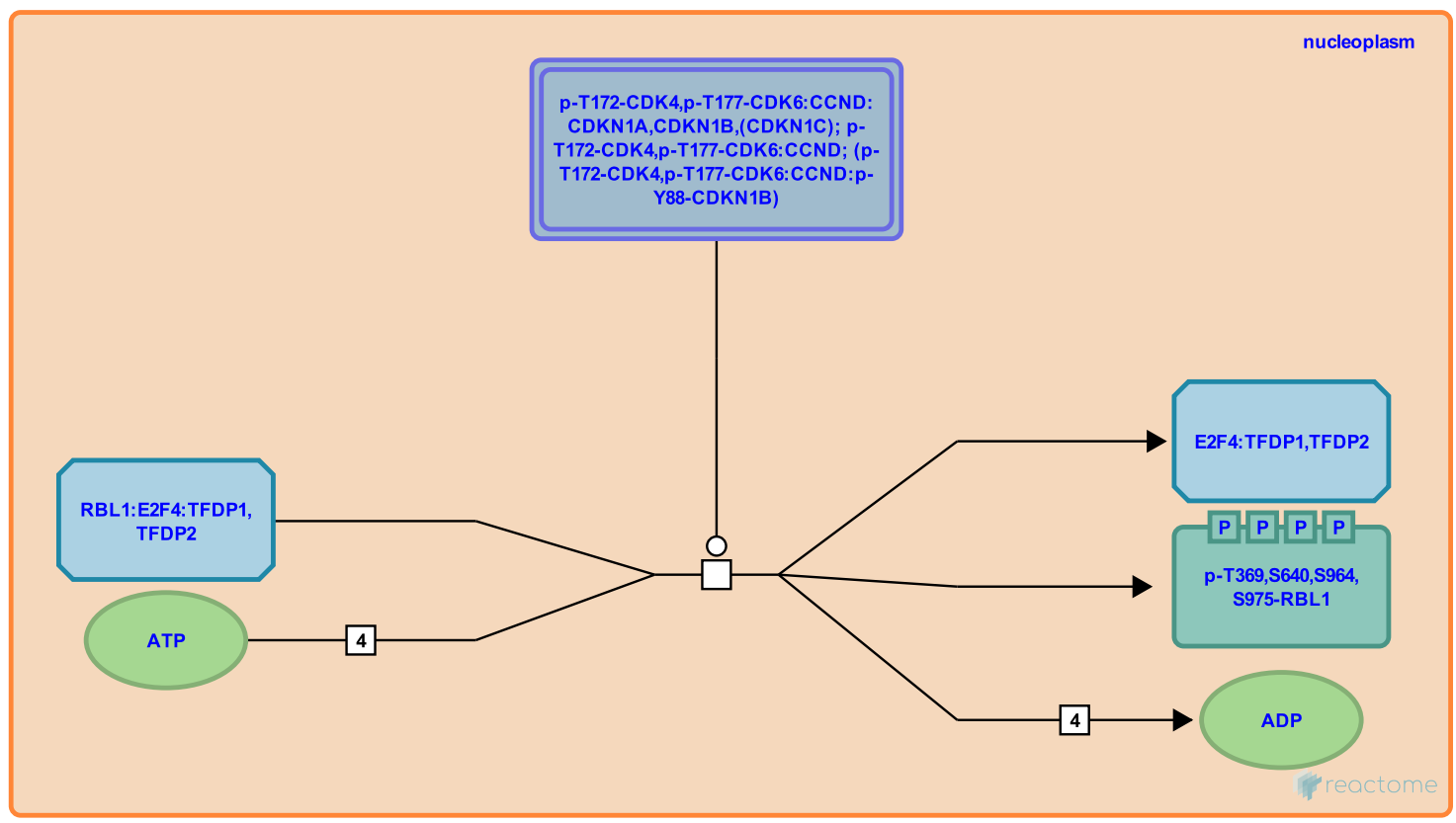

In late G1, cyclin D dependent kinases CDK4 and CDK6 phosphorylate RBL1 (p107) on four serine and threonine residues (S964, S975, T369 and S640), leading to dissociation of phosphorylated RBL1 (p107) from E2F4 in complex with either DP-1 or DP-2. E2F4, which lacks nuclear localization signal, is then thought to translocate to the cytosol, allowing E2F promoter sites to become occupied by activating E2Fs (E2F1, E2F2, and E2F3), resulting in transcription of E2F targets needed for cell cycle progression.

Preceded by: CDK4/6:CCND complexes are activated by T-loop phosphorylation of CDK4/6

Followed by: Dephosphorylation of p107 (RBL1) by PP2A

\section{Literature references}

Leng, X., Noble, M., Adams, PD., Qin, J., Harper, JW. (2002). Reversal of growth suppression by p107 via direct phosphorylation by cyclin D1/cyclin-dependent kinase 4. Mol Cell Biol, 22, 2242-54. 7

Beijersbergen, RL., Carlée, L., Kerkhoven, RM., Bernards, R. (1995). Regulation of the retinoblastoma protein-related p107 by G1 cyclin complexes. Genes Dev, 9, 1340-53. 7

Lindeman, GJ., Gaubatz, S., Livingston, DM., Ginsberg, D. (1997). The subcellular localization of E2F-4 is cell-cycle dependent. Proc Natl Acad Sci U S A, 94, 5095-100. 九

\section{Editions}

2011-06-14

2011-08-25
Authored

Reviewed
Orlic-Milacic, M.

MacPherson, D. 


\section{Dephosphorylation of p107 (RBL1) by PP2A $\nearrow$}

Location: Cyclin D associated events in G1

Stable identifier: R-HSA-1363274

Type: transition

Compartments: nucleoplasm

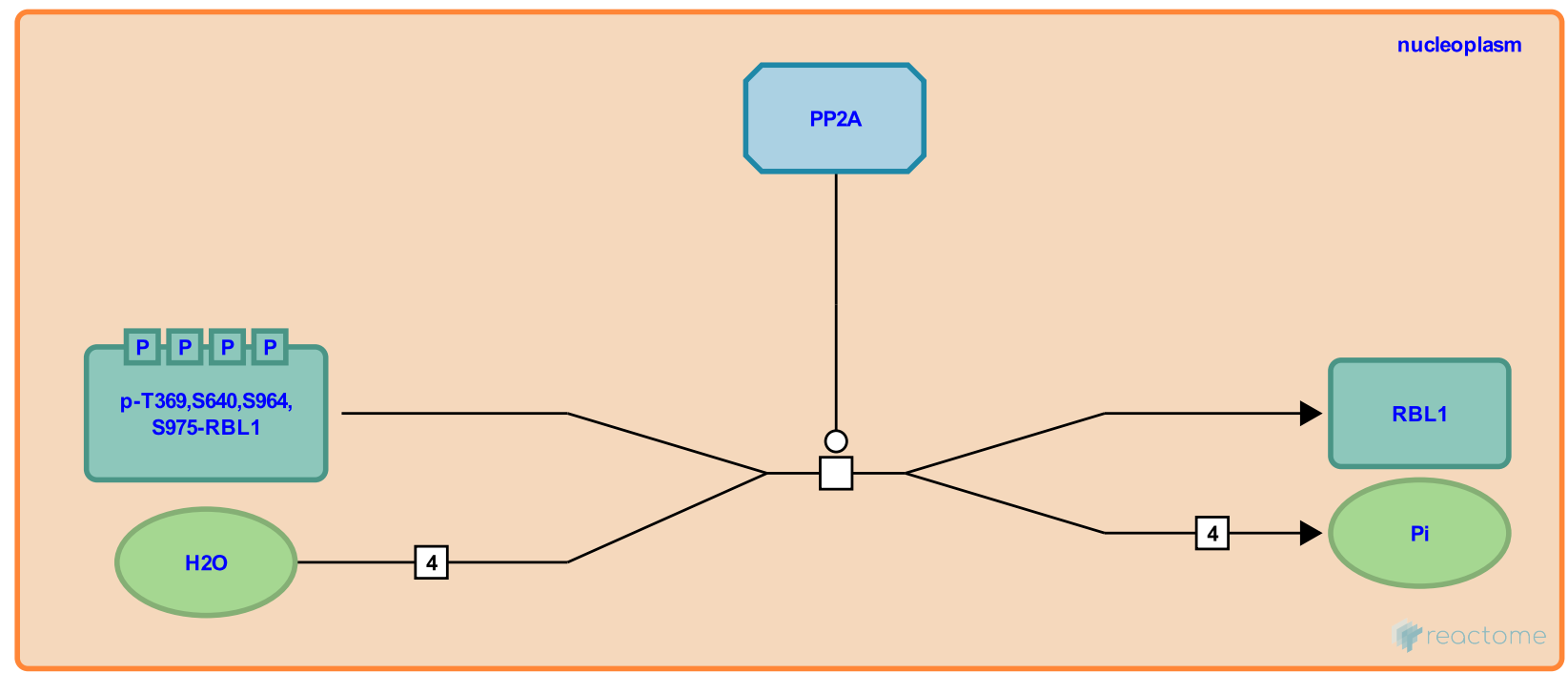

Dephosphorylation of p107 (RBL1) by PP2A complex containing either PPP2R3B (B" beta) or PPP2R2A (B alpha) regulatory subunit plays a role in maintaining the equilibrium of hyperphosphorylated and hypophosphorylated p107 (RBL1), through counteracting action of cyclin dependent kinases (CDKs) throughout the cell cycle. It is assumed that PP2A dephosphorylates p107 (RBL1) on all four phosphorylation sites, but further experiments are needed to confirm this.

Preceded by: Cyclin D:CDK4/6 mediated phosphorylation of p107 (RBL1) and dissociation of phosphorylated p107 (p-RBL1) from DP1:E2F4 complex

\section{Literature references}

Jayadeva, G., Kurimchak, A., Garriga, J., Sotillo, E., Davis, AJ., Haines, DS. et al. (2010). B55alpha PP2A holoenzymes modulate the phosphorylation status of the retinoblastoma-related protein p107 and its activation. J Biol Chem, 285, 29863-73. \

\section{Editions}




\section{Cyclin D:Cdk4/6 mediated phosphorylation of p130 (RBL2) and dissociation of phos- phorylated p130 (RBL2) from DP1:E2F4/5 complex $\lambda$}

Location: Cyclin D associated events in G1

Stable identifier: R-HSA-1226094

Type: transition

Compartments: nucleoplasm

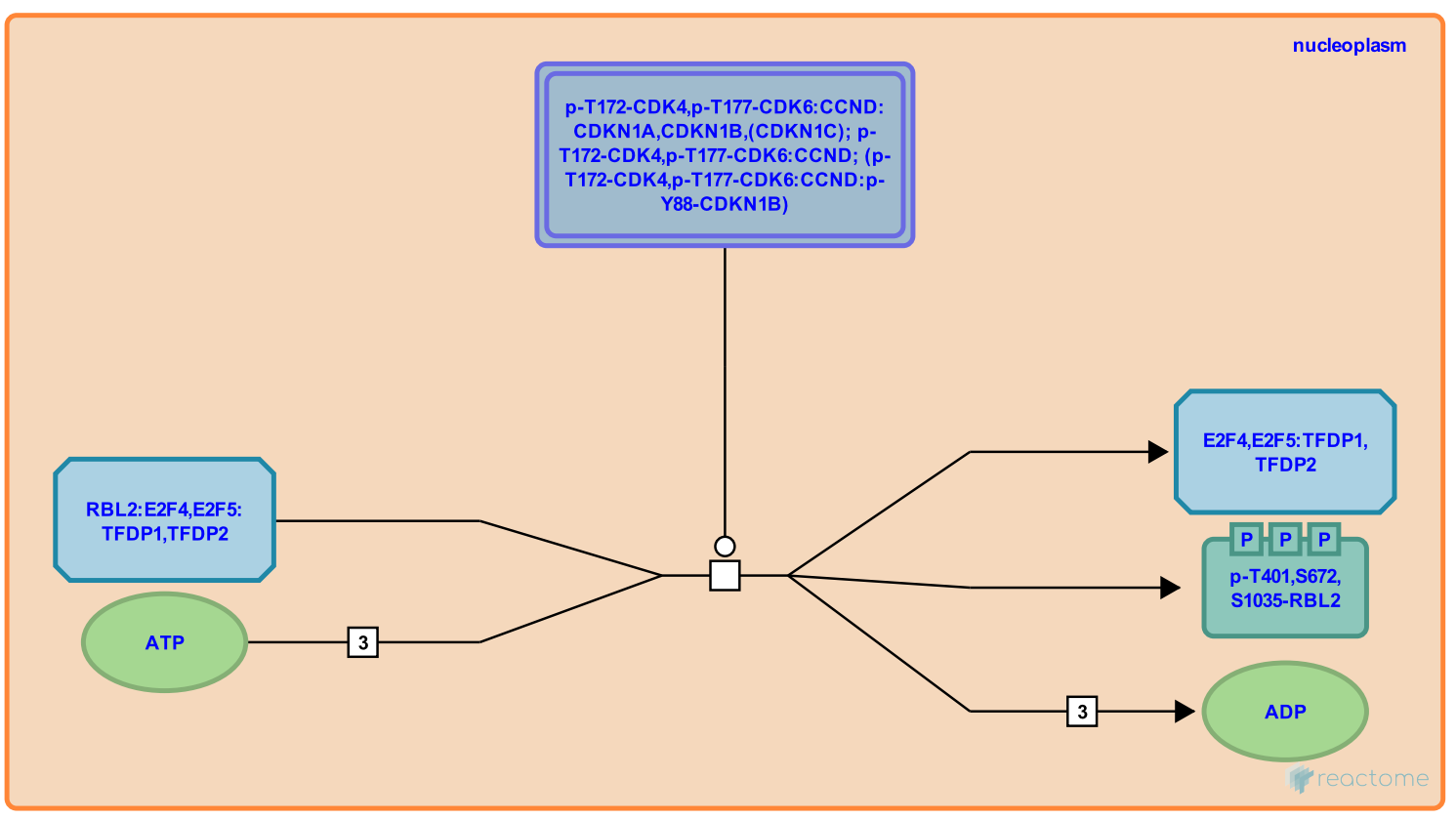

At G1 entry from G0, p130 (RBL2) is phosphorylated on three threonine and serine residues by cyclin D1 dependent kinases CDK4 and/or CDK6, leading to dissociation of p130 (RBL2) from complexes it formed with E2F4 or E2F5 and DP1 or DP2. This is thought to promote translocation of E2F4 and E2F5, which lack nuclear localization signals, to the cytosol, allowing activating E2Fs (E2F1, E2F2 and E2F3) to bind E2F promoters and activate transcription of genes needed for G1 progression.

Preceded by: CDK4/6:CCND complexes are activated by T-loop phosphorylation of CDK4/6

Followed by: Dephosphorylation of p130 (RBL2) by PP2A, Phosphorylated p130 (RBL2) binds SCF(Skp2):Cks1 complex

\section{Literature references}

Hansen, K., Farkas, T., Lukas, J., Holm, K., Rönnstrand, L., Bartek, J. (2001). Phosphorylation-dependent and -independent functions of p130 cooperate to evoke a sustained G1 block. EMBO J, 20, 422-32. ㅈ

Lindeman, GJ., Gaubatz, S., Livingston, DM., Ginsberg, D. (1997). The subcellular localization of E2F-4 is cell-cycle dependent. Proc Natl Acad Sci U S A, 94, 5095-100.

\section{Editions}

2011-06-14

2011-08-25
Authored

Reviewed
Orlic-Milacic, M.

MacPherson, D. 


\section{Dephosphorylation of p130 (RBL2) by PP2A $\nearrow$}

Location: Cyclin D associated events in G1

Stable identifier: R-HSA-1363276

Type: transition

Compartments: nucleoplasm

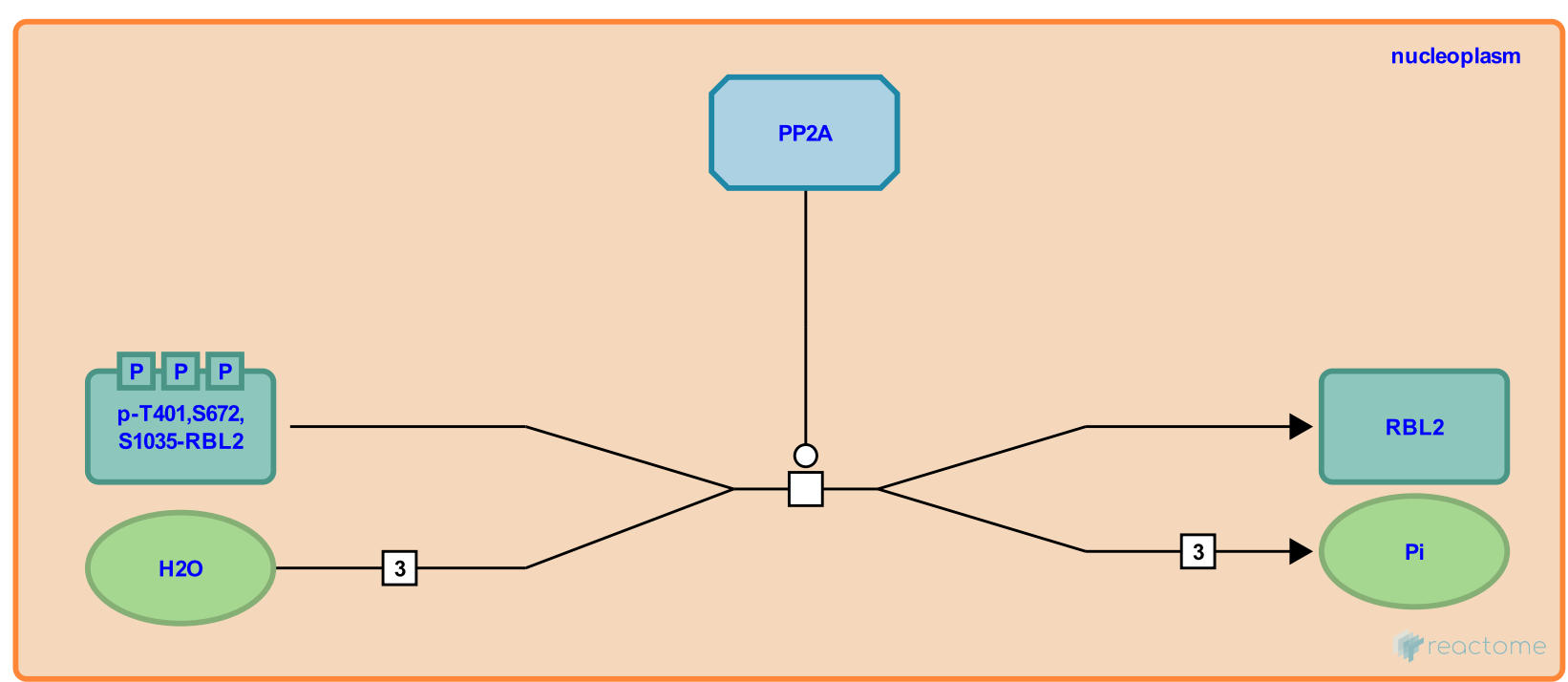

Dephosphorylation of p130 (RBL2) by PP2A complex containing either PPP2R3B (B" beta) or PPP2R2A (B alpha) regulatory subunit plays a role in maintaining the equilibrium of hyperphosphorylated and hypophosphorylated p130 (RBL2), through counteracting action of cyclin dependent kinases (CDKs). It is assumed that PP2A dephosphorylates p130 (RBL2) on all three phosphorylation sites, but further experiments are needed to confirm this.

Preceded by: Cyclin D:Cdk4/6 mediated phosphorylation of p130 (RBL2) and dissociation of phosphorylated p130 (RBL2) from DP1:E2F4/5 complex

\section{Literature references}

Jayadeva, G., Kurimchak, A., Garriga, J., Sotillo, E., Davis, AJ., Haines, DS. et al. (2010). B55alpha PP2A holoenzymes modulate the phosphorylation status of the retinoblastoma-related protein p107 and its activation. J Biol Chem, 285, 29863-73. $\lambda$

\section{Editions}

Orlic-Milacic, M. 


\section{Phosphorylated p130 (RBL2) binds SCF(Skp2):Cks1 complex $\lambda$}

Location: Cyclin D associated events in G1

Stable identifier: R-HSA-1363328

Type: binding

Compartments: nucleoplasm

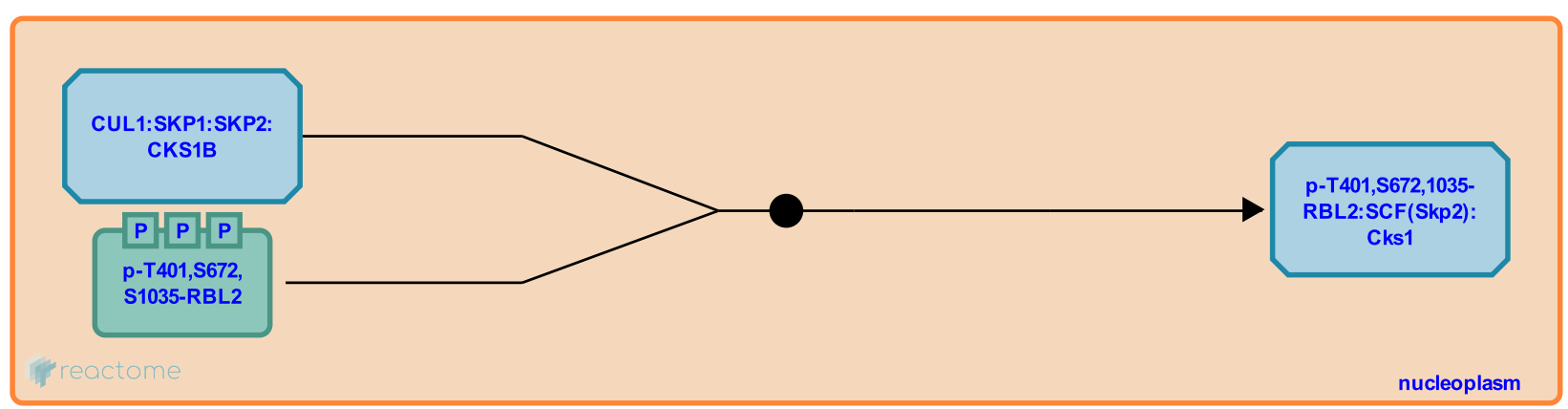

Phosphorylated p130 (RBL2) binds SCF (Skp2) ubiquitin ligase in complex with Cks1. Phosphorylation of p130 (RBL2) serine residue S672 by CDK4/6 is critical for this interaction.

Preceded by: Cyclin D:Cdk4/6 mediated phosphorylation of p130 (RBL2) and dissociation of phosphorylated p130 (RBL2) from DP1:E2F4/5 complex

Followed by: Ubiquitination of p130 (RBL2) by SCF (Skp2)

\section{Literature references}

Tedesco, D., Lukas, J., Reed, SI. (2002). The pRb-related protein p130 is regulated by phosphorylation-dependent proteolysis via the protein-ubiquitin ligase SCF(Skp2). Genes Dev, 16, 2946-57. 7

\section{Editions}

2011-06-14

2011-08-25
Authored

Reviewed
Orlic-Milacic, M.

MacPherson, D. 


\section{Ubiquitination of p130 (RBL2) by SCF (Skp2) $\lambda$}

Location: Cyclin D associated events in G1

Stable identifier: R-HSA-1363331

Type: transition

Compartments: nucleoplasm

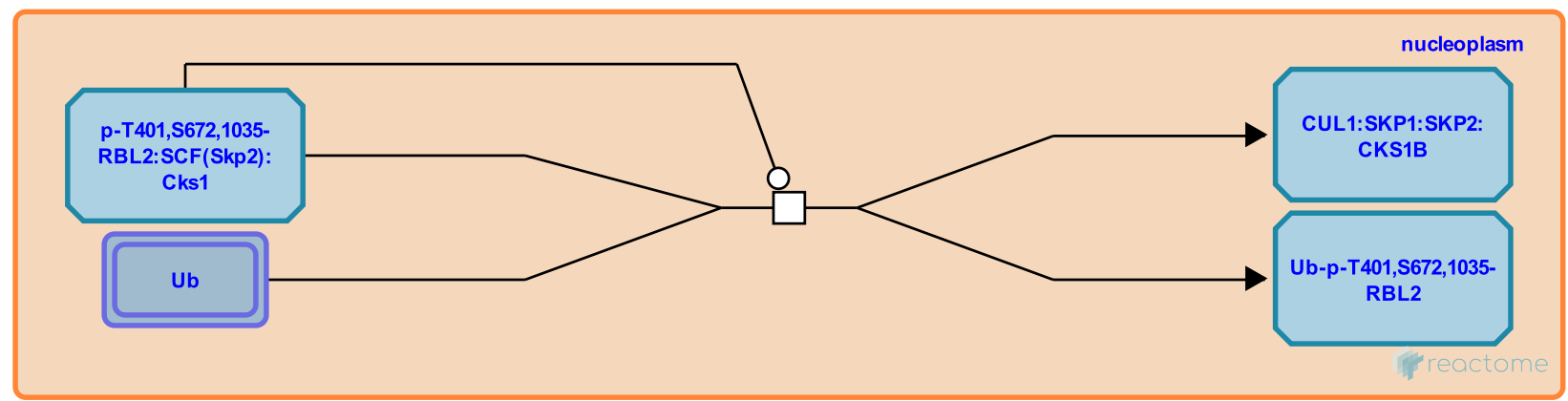

As quiescent G0 cells reenter the cell cycle, p130 (RBL2) is phosphorylated by CDK4/6. This phosphorylated p130 (RBL2) binds ubiquitin ligase SCF (Skp2) in complex with Cks1, and is subsequently ubiquitinated and degraded similarly to p27, which is another target of SCF (Skp2).

Preceded by: Phosphorylated p130 (RBL2) binds SCF(Skp2):Cks1 complex

\section{Literature references}

Tedesco, D., Lukas, J., Reed, SI. (2002). The pRb-related protein p130 is regulated by phosphorylation-dependent proteolysis via the protein-ubiquitin ligase SCF(Skp2). Genes Dev, 16, 2946-57. 7

\section{Editions}

2011-06-14

2011-08-25
Authored

Reviewed
Orlic-Milacic, M.

MacPherson, D. 


\section{Table of Contents}

Introduction 1

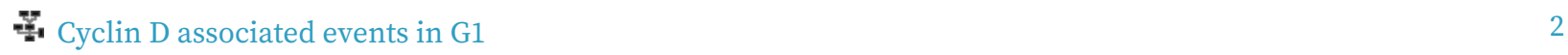

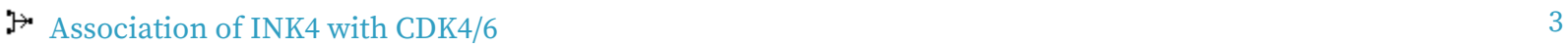

\$’ Formation of CDK4/6:CCND complexes 4

\$׳ Cip/Kip CDK inhibitors bind CDK4/6:CCND complexes 6

$\$ \ngtr$ Tyrosine kinases phosphorylate Cip/Kip inhibitors bound to CDK4/6:CCND complexes 7

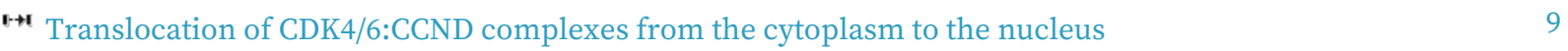

' $\gg$ CDK4/6:CCND complexes are activated by T-loop phosphorylation of CDK4/6

"ł RB1 binds and inhibits E2F1/2/3:DP1/2 complexes 13

" Cyclin D:CDK4/6 phosphorylates RB1 and prevents RB1 binding to E2F1/2/3:DP1/2 complexes 14

" Cyclin D:CDK4/6 mediated phosphorylation of p107 (RBL1) and dissociation of phosphorylated p107 15 (p-RBL1) from DP1:E2F4 complex

"ł Dephosphorylation of p107 (RBL1) by PP2A 16

" Cyclin D:Cdk4/6 mediated phosphorylation of p130 (RBL2) and dissociation of phosphorylated p130 17 (RBL2) from DP1:E2F4/5 complex

'¥* Dephosphorylation of p130 (RBL2) by PP2A 18

"ł Phosphorylated p130 (RBL2) binds SCF(Skp2):Cks1 complex 19

"ł Ubiquitination of p130 (RBL2) by SCF (Skp2) 20

Table of Contents 